Itinera Spiritualia

IX $\cdot 2016 \cdot 169-191$

Francisco Javier Sancho Fermín OCD

\title{
LA MÍSTICA TERESIANA COMO CAMINO DE HUMANIZACIÓN
}

\section{INTRODUCCIÓN}

Normalmente, cuando se habla de mística, parece que nos sumergimos en un ámbito de estudio que poco o nada tiene que ver con la ciencia, especialmente cuando hablamos de ciencia en un sentido reduccionista, tal como el que generalmente usamos en el contexto actual, restringido a la dimensión empírica y positivista.

No obstante, y de manera a veces sorprendente, la ciencia en sus diversas disciplinas, no ha dejado de interesarse -especialmente a partir del siglo XXen la mística en cuanto fenómeno humano peculiar. Algunos, desde el ámbito médico y psiquiátrico, se han esforzado demasiado en estudiar la fenomenología mística, con el ánimo de demostrar disfunciones psíquicas en los sujetos que han padecido o padecen dichos fenómenos. Otros, más objetivos y con un sentido científico más serio, han tenido el acierto de no caer en un reduccionismo de identificación de los fenómenos extraordinarios con la enfermedad mental o neuronal $\mathrm{l}^{2}$. Lo cierto es, que tanto desde una perspectiva como desde la otra, la atención hacia el místico y sus experiencias se ha constituido en un campo de estudio $^{3}$. Algo semejante ha acontecido en otras áreas del saber: la antropología, la

1 Para las citas de los textos de Teresa de Jesús seguimos la edición preparada por el P. Tomás Alvarez: Obras completas, Monte Carmelo, Burgos 1997 ( $8^{\mathrm{a}} \mathrm{ed}$.). Hacemos uso de las siglas habituales para citar los escritos de la Santa: V: Libro de la Vida; C: Camino de Perfección; F: Fundaciones; M: Moradas del Castillo Interior. Los números hacen alusión al capitulo y al párrafo sucesivamente. Al citar el libro de las Moradas el número que precede a la sigla indica la morada correspondiente.

2 Una presentación de estudios en estos ámbitos ha sido recopilada y criticada por el gran teresianista T. Alvarez, Santa Teresa a contraluz. La Santa ante la crítica, Burgos 2004.

3 Una muestra de la riqueza que aporta la mística al conocer humanista es la obra del psiquiatra 
filosofía, la psicología en sus múltiples corrientes, etc... Por no hablar de otros campos de las humanidades como la fenomenología, la historia, el arte, la literatura, etc..., que han descubierto en los místicos un campo de especial atención.

Surge, en este ámbito del saber, una problemática que también ha sido y es abordada desde diversos puntos de vista y con resultados múltiples: si la mística tiene un estatuto epistemológico propio, si la mística o el estudio de la mística en toda su amplitud puede llegar a designarse como "ciencia", etc... Ciertamente no es este el lugar para intentar abordar estas cuestiones, ni siquiera someramente. Pero sí creo de suma importancia considerar que hay un ámbito de estudio al que es posible acercarse con una metodología científica y empírica, y en el cual la mística y/o los místicos pueden ofrecer, y de hecho ofrecen, unos resultados importantes a la hora de conocer y plasmar conclusiones que afectan a un conocimiento más profundo y veraz de quién es el ser humano. Quizás, no es posible llegar a conclusiones lógicas-empíricas de lo que es el Misterio que acontece como experiencia en el místico, pero sí podemos prestar atención a los resultados que quedan plasmados en su vida y en su saber, y que remiten mayoritariamente a una comprensión de lo que es el ser humano, que no se contradice con otros ámbitos del saber, sino que incluso los ilumina y precede en sus conclusiones. Ciertamente aquí se abre un campo de estudio muy amplio y en el que ya se está investigando.

En ciertos estudios, que parecen obsesionarse con tratar de evidenciar disfunciones y enfermedades en los místicos, resulta evidente que el punto de partida, aparte de ser poco científico, es equivocado. Se pretende explicar con argumentos racionales lo que generalmente se escapa a ese campo. Cuando quizás, el punto de partida más lógico, tendría que ser el de los efectos y consecuencias que todo ello produce en el sujeto de la experiencia mística. En este sentido hoy día hay numerosos estudios y experimentos de laboratorio que nos hablan de los efectos beneficiosos, por ejemplo, de la meditación: una mayor salud psíquica, una mejor disponibilidad a superar las dificultades, una mayor capacidad de resiliencia, una actitud humana más positiva, y hasta una interacción directa entre el pensar positivo y efectos biológicos y neuronales para la persona; hasta se afirma que una práctica de la meditación constante influye en la dermis del sujeto.

Todo este discurso previo busca, sencillamente, contextualizar el acercamiento que pretendemos hacer en este artículo a la comprensión que Teresa de Jesús nos ofrece sobre el ser humano y su dignidad. No nos interesa tanto la an-

J. Sanchez-Caro, Intimidad y misticismo en Teresa de Jesús, Ávila 2005. Otro estudio desde la medicina es: B. Souvignier, La dignidad del cuerpo. Salvación y sanación en Teresa de Jesús, Madrid 2008. 
tropología subyacente, que ha sido de sobra estudiada y puesta en evidencia Una antropología que, como es natural, se corresponde a la visión y concepción características del lenguaje filosófico y teológico de su tiempo, también condicionada por una visión social peculiar. Lo que verdaderamente nos interesa aquí es evidenciar el concepto de ser humano al que Teresa llega, no tanto por el camino intelectual, cuanto por el camino experiencial de la interioridad humana, que se verá favorecido y potenciado en ella, no desde la simple observación, sino desde la apertura a la experiencia de Dios. De ésta no hablamos, pero sí de los resultados a los que le va a ir llevando.

\section{LA EXPERIENCIA MÍSTICA COMO FUENTE DE SABER ANTROPOLÓGICO}

El filósofo español Ortega y Gasset definía la sabiduría como la "cantidad de

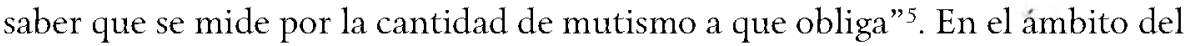
saber místico esto resulta evidente, tanto por la perspectiva de una teología negativa o apofática, como desde el punto de vista de la inefabilidad de la experiencia del Misterio que obliga a callar. Sin embargo, algunos de los grandes místicos parecen hacer lo contrario. Aún en el silencio de lo que no se puede contar, emerge la necesidad de transmitir un mensaje, de contagiar una experiencia.

Posiblemente no se pueda llegar a hacer una demostración de la experiencia mística en cuanto tal. Pero hay otra vía que, al menos, nos acerca desde el ámbito experimental y experiencial, a permanecer en silencio frente a lo incomprensible. Si algo caracteriza la experiencia y saber de los místicos es su propia vida, es decir, el cambio, efectos y transformación que produce en ellos esa "experiencia inefable". Si el misterio no se puede narrar en su totalidad, la vida, los frutos y efectos, se convierten en el criterio de una "sabiduría de vida" que distingue al místico verdadero, y no los fenómenos en sí, cuya complejidad no siempre favorece un acercamiento objetivo a los mismos, ya que necesitarían de un tratamiento con carácter interdisciplinar.

Pensemos en una Madre Teresa de Calcuta. Para la gran mayoría su experiencia de Dios es totalmente desconocida, y el sentido de sus "noches" aún más. Un Dios que se manifiesta y revela en el silencio y que aún en la experiencia de la ausencia forja unos frutos de entrega y de amor que dan sentido ejemplar a una vida. La Madre Teresa de Calcuta nos ha hablado de Dios a través de su entrega amorosa. Su vida estuvo marcada por la sabiduría del amor, que, sin embargo, no se entiende como un simple voluntarismo humano. Teresa de Jesús

4 Uno de los estudios más recientes sobre este tema es el de A. Serrano, Una Propuesta de Antropología Teológica en el 'Castillo Interior' de Santa Teresa, Ávila 2011.

5 El Expectador, Tomo VII, Espasa Calpe, Madrid 1966, p. 83. 
y otros muchos insisten en que el efecto que nos habla de una auténtica experiencia de Dios es el amor al prójimo. El misterio no podremos identificarlo, pero la entrega de la persona es algo observable desde la experiencia, algo que entra en lo experimentable. Uno se puede preguntar el porqué de esa entrega generosa, y hasta puede llegar a sacar sus conclusiones. Preguntarse por la fuente de esa energía que se da libre y gratuitamente, cuanto menos nos lleva a una postración silenciosa ante un misterio que funda esos efectos. Teresa de Jesús ha sido tachada de mujer enferma, epiléctica, etc..., y sin embargo, fue capaz de fundar 17 conventos, de escribir grandes tratados, de tratar con gente de todos los niveles sociales, y de sobrevivir en medio de una sociedad machista y clasista, manteniendo intacta su humanidad y su atención a las necesidades de su tiempo.

Teresa de Jesús, tratando de dar razón al sentido de la vida mística, diría que „para esto es la oración: de que nazcan siempre obras, obras" ${ }^{\circ}$. La progresiva transformación de la persona, su entrega a los otros sin intereses de ningún tipo, delatan una "sabiduría de vida anclada en el amor", y lleva a un reconocimiento de que esos efectos tienen una causa, aunque uno no pueda llegar a constatarla o evidenciarla racionalmente. Pero el modo de vivir es siempre el mejor argumento del modo de ser. Y efectos como los que constatamos en Teresa o en otros místicos, no pueden justificarse simplemente en base a ideales o actitudes enfermizas que, generalmente llevan a un replegamiento de la persona.

Pero el saber místico no se reduce sólo a una serie de fenómenos extraordinarios y al conocimiento del misterio de Dios. Antes pasa por el conocimiento del hombre, en su interioridad más profunda, en su dignidad, en el sentido de su propia vida y existencia. Ni la ciencia, ni la razón especulativa, han sido capaces de llegar tan hondo en la comprensión de la interioridad humana. El mismo subconsciente que, en gran medida permanece como una intriga misteriosa para los psicólogos, encuentra soluciones y respuestas positivas en el minucioso conocimiento que muchos místicos manifiestan de los mecanismos psicológicos y espirituales del ser humano ${ }^{7}$.

No se trata, pues de un saber que se cierre a lo inefable del misterio, sino que se abre a lo concreto y que afecta a todo ser humano. Mecanismos de sobrevivencia ante cualquier situación, frente a los cuales ni la persona humanamente más madura o psicológicamente más perfecta, es capaz de resistir y fortalecerse.

Pero este saber no es simplemente teórico. Termina fundamentando la capacidad de conocerse, de aceptarse, y, aún más, de amarse. Actitud sabia que le coloca al hombre frente a sí mismo y frente a los otros en la misma clave relacional y de conocimiento. Santa Teresa de Jesús decía que el "conocimiento de sí es

$7 \mathrm{M} 4,6$.

Un acercamiento interdisciplinar a la mística puede verse en el trabajo conjunto dirigido por la psiquiatra M. Rodríguez, La experiencia mística, Burgos 2013. 
el pan con que se han de comer todos los manjares", y que sin este alimento no se puede uno sustentar en el camino espiritual-místico del encuentro con Dios.

Si de la contemplación de la naturaleza emerge la ciencia, la comprensión de los mecanismos físicos y químicos, de la contemplación del ser interior emerge una ciencia y sabiduría que ayuda al hombre a ser hombre, y a colocarse como tal frente a los demás. Una objetividad que surge de la contemplación de la vida, y de la abstracción-sistematización de la misma. En un proceder que puede ser tan escrupuloso o más en su análisis y metodología como el de cualquier rama del saber.

De hecho muchos místicos han hecho ese esfuerzo por desvelar, escribir y sistematizar, al menos en parte, los resultados de ese "conocimiento interior" del ser humano, gracias a su propia experiencia y a la experiencia que otros les han compartido. Y en gran medida todo ello es lo que suscita la gran curiosidad por parte de filósofos, teólogos, psicólogos, científicos, etc... Por esta vía podemos acceder, quizás más sistemáticamente, a los resultados a los que ellos llegaron a través de la vida y de la experiencia. Para el mismo Unamuno, es lo que define el gran legado de Teresa para la humanidad: "Otros pueblos nos han dejado sobre todo instituciones, libros; nosotros hemos dejado almas. Santa Teresa vale por cualquier instituto, por cualquier Crítica de la razón pura"s.

En este campo de un saber experiencial que pone en evidencia un conocimiento real, observable y constatable de lo que es el hombre desde dentro, se podría decir que la experiencia mística tiene en sus manos unos instrumentos eficaces para una transformación posible de la sociedad. Ello se debe a que el saber místico tiene en sus manos un saber ligado estrechamente al saber auténticamente humano, y por lo tanto es conocedora de una vía que puede ayudar al hombre a transformar su existencia, llenándola de sentido y dignidad.

Por eso, conocer la vida íntima del alma, gracias a la "experiencia de los místicos" nos abre un mundo que de otro modo permanecería demasiado desconocido. Aún en el mismo conocimiento de sí, la persona que quiera llegar al más profundo centro de su ser, del sentido de la vida y de su libertad, necesita realizar un camino que pasa por la interiorización. La filósofa fenomenóloga Edith Stein, discípula y asistente de Husserl en la universidad de Freiburg, afirmaba:

Pero no es posible ofrecer un cuadro preciso del alma -ni tan siquiera de forma somera y deficiente- sin llegar a hablar de lo que compone su vida íntima. Para ello, las experiencias fundamentales sobre las que hemos de basarnos son los testimonios de los grandes místicos de la vida de oración. Y en tal calidad, el "Castillo interior" es insuperable: ya sea por la riqueza de la

8 M. De Unamuno, Del sentimiento trágico de la vida, Obras Completas, VII, 298. 
experiencia interior de la Autora, que cuando escribe ha llegado al más alto grado de vida mística; ya sea por su extraordinaria capacidad de expresar en términos inteligibles sus vivencias interiores, hasta hacer claro y evidente lo inefable, y dejarlo marcado con el sello de la más alta veracidad; ya sea por la fuerza que hace comprender su conexión interior y presenta el conjunto en una acabada obra de arte ${ }^{9}$.

Nuestra atención se va a dirigir precisamente a esta obra de las Moradas, con el ánimo de señalar unas líneas generales y fundamentales en la comprensión que Teresa de Jesús nos ofrece del hombre concreto, no en clave teórica sino experiencial ${ }^{10}$.

\section{Punto de partida: el CONOCimiento y experiencia DE LA PROPIA HUMANIDAD}

Es de sobra conocido que Teresa de Jesús fue una mujer muy presente en su tiempo, en su ambiente, y en su realidad histórica. Aun siendo una "monja de clausura" tuvo noticia amplia de cómo se desarrollaba la vida, no sólo en su entorno familiar, monacal o local, sino que le llegaron informaciones de cómo se desarrollaba la vida social, política y religiosa en la España de Carlos V y Felipe II, pero también fuera de España, tanto en el ámbito europeo, con sus cambios y luchas de religión, como en el ámbito de las Américas, bien por noticias directas de sus hermanos que emigraron al nuevo continente a hacer fortuna, o bien por relatos de misioneros que traían ofrecían mayores detalles de cuanto estaba aconteciendo ${ }^{11}$.

De hecho, Teresa no parece ser indiferente ante las muchas "barbaridades" que se cometen en un lugar y en otro. Realidades que no sólo le preocupan y critica, sino frente a las cuales ella misma trata de plantearse cuáles son las causas o la razón última del por qué todo eso acontece. En una carta a su hermano Lorenzo, por entonces viviendo en Quito (Ecuador), Teresa le dice:

... que esto es lo que mucho me lastima, ver tantas perdidas, y esos indios no me cuestan poco. El Señor los dé luz, que acá y allá hay harta desventura;

9 E. STeIn, El castillo interior, en Id., Obras Completas, vol. III, Burgos 2007, pp. 1112-1113.

10 Ciertamente la comprensión y visión que nos presenta Teresa de Jesús de lo que es el hombre y su vida interior es muchísimo más amplia y rica de lo que vamos a dibujar en estas páginas. Nuestra pretensión es acercarnos a aquellos elementos que en la experiencia de Teresa mejor definen y concretan el ser y la vida de la persona humana.

11 Una lectura de su epistolario nos hace ver muy de cerca esta inmersión. También hay claros ecos de la situación en Libro de la Vida y Fundaciones. 
que como ando en tantas partes y me hablan muchas personas, no sé muchas veces qué decir, sino que somos peores que bestias, pues no en tende mos la gran dignidad de nuestra alma, y cómo la apocamos con cosas tan apocadas como son las de la tierra. Denos el Señor luz ${ }^{12}$.

"No entendemos la dignidad de nuestra alma". Hacia esta afirmación confluyen todas las situaciones de injusticia que rigen el funcionamiento de la sociedad humana. Se puede hablar de muchas causas y razones, pero en el fondo todas terminan remitiendo a ese principio: en última instancia la razón del comportamiento está condicionada por cómo nos vemos a nosotros mismos y, en consecuencia, cómo percibimos a los otros seres humanos. Estamos frente a una causa que se asienta en el mismo hombre: en el desconocimiento que tiene de su propio ser, de lo que da el verdadero sentido y fundamenta su dignidad. No es extraño que Teresa diga que somos "peores que bestias".

En la identificación del fundamento que ya Teresa intuye en el siglo XVI, hoy las ciencias humanas terminan por darle toda la razón. Así por ejemplo, desde la psicología transpersonal se concibe el crecimiento personal como un proceso de "auto-construcción" y "auto-reconocimiento" como individuo en relación, está convencido de que "la recuperación de esos valores universales que deben ser "vividos" y no pensados de manera intelectual, puede realizarse mediante -lo que este autor denomina- las "cuatro puertas para trascender el yo". En ellas se resumen los diferentes caminos espirituales que han sido explorados por los sabios y místicos de todos los tiempos"13. Y desde la antropología, por ejemplo el Dr. Pedro Cerezo Galán, no ahorra palabras para asegurar que "en el libro de la Vida (de Santa Teresa de Jesús) está el acta de nacimiento de la intimidad moderna" ${ }^{14}$.

El hecho de que Teresa y muchas de las diversas corrientes humanistas actuales apunten a la necesidad de rescatar la "dignidad de la persona humana", nos colocan en la línea de desarrollo de este artículo. De la mano de Teresa de Jesús, y desde lo que fue su camino experiencial, vamos a tratar de identificar aquello sobre lo cual ella consigue fundamentar la dignidad inalienable del ser humano. Posiblemente ninguna corriente humanista en sí misma sea capaz de llevar a esos términos la comprensión del ser humano en su riqueza y valor infinitos. Vamos a descubrir cómo el camino de la mística termina fundamentando y fundamentándose en el descubrimiento del ser humano en su ser único e insustituible.

12 Carta a Lorenzo de Cepeda, 17 de enero de 1570, n. 13.

13 F. Rodríguez Bernaechea, Trascender el ego, en M. Rodríguez-Zafra, Crecimiento personal: aportaciones de Oriente y Occidente (Colección Serendipiy 98), Bilbao 2004, p. 252.

14 P. Cerezo Galán, La experiencia de la subjetividad en Teresa de Jesuis, en La recepción de los místicos Teresa de Jesús y Juan de la Cruz, Salamanca 1997. 
Por eso, tampoco resulta extraño que la psicología coincida con Teresa de Jesús al subrayar -tal como iremos presentando- que la piedra angular sobre la que se construye el edificio de la persona y su felicidad es el conocimiento de sí misma, y la consecuente aceptación de su propia verdad. Hablar del conocimiento de sí o hablar del propio conocimiento es adentrarse en un tema que nos toca a todos de una manera fuertemente existencial. Y por muchos años que vivamos no llegamos nunca a alcanzar un conocimiento propio total y exhaustivo de nuestro ser y de nuestra personalidad. Es el misterio que envuelve siempre y continuamente la vida de todo ser humano. Del grado de conocimiento propio que alcancemos depende, -según el parecer de la gran mayoría de las escuelas de psicología actuales-, todo o casi todo en nuestra existencia. Y lo más importante: de ello depende nuestra realización como personas felices y satisfechas consigo mismas. No en vano, la psicología moderna lo subraya como uno de los elementos fundamentales a tener en cuenta de cara a una buena salud psíquica y espiritual.

Posiblemente estamos frente a un tema fundamental, no sólo en el desarrollo de la misma persona, sino en cuanto a su capacidad de relación con los otros. No conocerse y no aceptarse supone una dificultad enorme de cara al éxito de las relaciones consigo mismo, con los otros, con la realidad.

El conocimiento propio termina siendo un pilar fundamental en todo el camino místico y espiritual, tanto para Teresa de Jesús como para otros místicos de su escuela (así Juan de la Cruz ${ }^{15}$ o Edith Stein ${ }^{16}$ ). Todo en la vida del hombre depende de este factor: una relación auténticamente humana con el mundo, con

15 El mismo Juan de la Cruz, en el momento de trazar el recorrido completo del camino espiritual en su obra maestra Cántico Espiritual, no duda en subrayar la importancia del conocimiento de sí -y en quéconsiste el mismo-para que pueda darse todo el proceso de crecimiento o seguimiento. Así leemos en el comentario a la estrofa primera del Cántico (CB 1, 1): "Cayendo el alma en la cuenta de lo que está obligada a hacer, viendo que la vida es breve (Sant. 14, 5), la senda de la vida eterna estrecha $(\mathrm{Mt} 7,14)$, que el justo apenas se salva $(1 \mathrm{Pe} .4,18)$, que las cosas del mundo son vanas y engañosas, que todo se acaba y falta como el agua que corre (2Re. 14, 14), el tiempo incierto, la cuenta estrecha, la perdición muy fácil, la salvación muy dificultosa; conociendo, por otra parte, la gran deuda que a Dios debe en haberle criado solamente para sí, por lo cual le debe el servicio de toda su vida, y en haberla redimido solamente por sí mismo, por lo cual le debe todo el resto y respondencia del amor de su voluntad, y otros mil beneficios en que se conoce obligada a Dios..." En una admirable síntesis nos ofrece el Santo en este texto los elementos que componen y explican sustancialmente ese conocimiento de sí, un conocimiento de la verdad teologal del hombre. En el comentario a la estrofa cuarta $(C B), 1)$ explícitamente concede al conocimiento de si el primer lugar en el proceso espiritual. También véase el $1^{\circ}$ libro de la Noche Oscura $(12,5)$.

16 La filósofa Edith Stein va a dedicar al tema hermosas páginas en sus trabajos antropológicos A lo largo de esta exposición acudiremos en varias ocasiones a ella. Pensamos que por su conocimiento de la espiritualidad teresiana y su interés por la antropología espiritual, nos ofrece muchos elementos que completan y clarifican el pensamiento de Teresa. 
los otros, dependerá del grado de interioridad alcanzado. Estamos, pues, frente a la clave de fundamentación del humanismo teresiano.

Cuando Teresa escribe su gran síntesis (con más de 60 años de edad), el libro de Las Moradas, ya tiene un conocimiento completo de todo el camino espiritual y una muy probada experiencia mística, que le hace capaz de diseñar todo el proceso atendiendo a los elementos fundamentales y principales del proceso. El punto de partida, caracterizado por la entrada decidida en el camino de la meditación o de la oración mental, va acompañado del insustituible conocimiento de sí, al que la Santa le va a conceder un rol particular: "primero da el Señor un gran conocimiento propio que hace estas mercedes"17, es decir, sin conocimiento de sí no hay posibilidad de adentrarse en una duradera y auténtica experiencia mística.

Si los estudiosos de la fenomenología mística prestasen atención a estas afirmaciones teresianas, seguramente su modo de proceder y las conclusiones a las que llegan serían muy diferentes. Lo que está en juego no es el fenómeno, sino la realización integral de la persona. Y es lo que le interesa al místico auténtico. Por eso se habla del "socratismo teresiano", rememorando la gran intuición de Sócrates que invita al "conócete a ti mismo"18.

La psicología moderna y la pedagogía no se cansan de insistir en la importancia de la aceptación de uno mismo. Sin este presupuesto las relaciones "ad extra" (con el mundo y con los otros) fácilmente adquieren matices enfermizos. Se afirma desde la psicología que el hombre actúa desde la visión o comprensión que tiene de sí. ¿Cómo puede amarse quién no se conoce o no se acepta? ¿Cómo será su amor al otro? ¿Con qué medida se enfrentará a él? El tema no es pues, sólo una realidad psicológica, sino profundamente, sustancialmente, humana, y por lo tanto religiosa y espiritual ${ }^{19}$. Pedro Cerezo Galán, refiriéndose al papel de los místicos en su tiempo, afirma:

Pero a la vez, esta reforma no era arcaizante, esto es, no se producía a la contra del espíritu de su tiempo, sino en sintonía con las nuevas

$176 \mathrm{M} 9,15$.

18 Afirma el T. Alvarez, Guía al interior del Castillo. Lectura espiritual de las "Moradas", Monte Carmelo, Burgos 2000, p. 32: "Sí, es espontánea esa evocación del gran filósofo griego. Él no sólo había aceptado la consigna pragmática del oráculo de Delfos -"iconócete!"- sino que le había dado una versión profunda, cercana al evangelio de Jesús. A uno de sus discípulos predilectos, el joven Alcibiades, Sócrates le explica que para conocerse a sí mismo no le basta conocer su cuerpo, tiene que conocer el alma de Alcibíades. Y nollegará a conocer su alma, si no conoce esa pequeña centella de divinidad que hay en ella."

19 Edith Stein en su obra Potenz und Akt (ESW XVIII), p. 90, afirma: "Vivir espiritualmente significa, además, darse cuenta de este movimiento, ser trasparente para sí mismo, ser consciente de sí mismo y tal vez de otro". 
tendencias a la humanización del mundo y la individua-

lización del yo, constitutivas del Renacimiento ${ }^{20}$.

Bastaría con tener presente la imagen en base a la cual Teresa construye el camino de la oración, para percatarnos de la importancia del tema. Cuando habla del hombre (o del alma) como de un castillo, y presenta el camino de la oración como un adentrarse en el mismo hasta la conquista del centro, en el fondo no hace más que trazar un camino místico en sintonía con el camino de conquista-conocimiento de sí. "No sé si queda dado bien a entender, porque es cos a tan importante este conocernos que no querría en ello hubiese jamás relajación, por subidas que estéis en los cielos" ${ }^{21}$. Teresa nunca deja de lado la dimensión humana del sujeto. Antes parece ser un requisito indispensable para dar solidez y autenticidad al camino místico.

Detrás de esta insistencia y de la importancia que da Teresa a este aspecto se esconde una concepción del ser humano en clave teologal y positiva. Teresa parte del principio, fruto de su propia experiencia, de que Dios habita en el centro del alma ${ }^{22}$; que no estamos huecos, sino que estamos habitados ni más ni menos que por el Infinito. La implicación directa es que la persona humana adquiere el valor del mismo Dios. Teresa, se presenta así como la gran humanista, porque vive convencida de la dignidad del ser humano, a imagen y semejanza del mismo $\operatorname{Dios}^{23}$. La fuerza que adquiere el fundamento del conocimiento de sí en el camino místico lo subrayaba ya Teresa en su primera obra escrita:

... esto del conocimiento propio jamás se ha de dejar,..; porque no hay estado de oración tan subido, que muchas veces no sea necesario tornar al principio, y en esto de los pecados y conocimiento propio, es el pan con que todos los manjares se han de comer, por delicados que sean, en este camino de oración, y sin este pan no se podrían susten$\operatorname{tar} \ldots{ }^{24}$

Hay que señalar, sin embargo, que cuando Teresa habla del conocimiento de sí, ciertamente no está pensando en una realidad simplemente cognoscitivo-psicológica. Y aquí radica la genialidad de la mística teresiana, que sin tener unos presupuestos científicos de lo que constituye la base de un crecimiento armónico de la personalidad, su experiencia mística de Dios le abre los ojos frente

20 P. Cerezo Galán, La experiencia de la subjetividad en Teresa de Jesús, en La recepción de los místicos Teresa de Jesís y Juan de la Cruz, Salamanca 1997, p. 171.

$21 \quad 1 \mathrm{M} 2,9$.

22 Cfr. por ejemplo: V 40, 6; C 28, 11. También, en referencia a Cristo: C 28, 2.

23 Cfr. $1 \mathrm{M} 1,1$

$24 \mathrm{~V} 13,15$. Esta misma importancia aparece subrayada en: V 15, 2-3.8; $1 \mathrm{M} \mathrm{1,2.}$ 
a esa realidad, de tal modo que su mística descubre aquí un factor que no le hace abstraerse de la realidad humana, sino que la asume, la presupone y la encamina hacia la plenificación total.

El conocimiento propio en el que con gran fuerza insiste Teresa es descubrimiento y toma de conciencia de la propia realidad esencial y existencial. Aun centrando la mirada sobre el "yo", el conocimiento de sí es el presupuesto que nos lleva a romper con el egoísmo y a ensanchar el panorama del propio mundo en la alteridad. Un conocimiento de sí que se abre al infinito del Misterio que es el único capaz de fundamentar de manera infinita e inalienable el inquietante misterio del hombre, que ha tenido siempre intrigada la mente del pensador, filósofo o no, que busca un sentido o razón de ser a la existencia del hombre ${ }^{25}$. El fundamento que encuentra Teresa a la comprensión del ser humano eleva al máximo el sentido de su propia dignidad. No emerge de una realidad caduca, temporal, ni siquiera es algo que le deba ser dado por un sistema, una institución o un estado. La dignidad le pertenece al hombre como su propia naturaleza, y por eso está muy por encima de ideologías o condicionantes temporales e históricos. Uno puede estar de acuerdo o no con las creencias religiosas de Teresa. Pero nadie puede negar, que dentro de la dinámica que ella plantea, no se puede dar un fundamento más sólido al valor del ser humano.

Descubrir esa dignidad del ser humano contrarresta cualquier otra actitud negativa que puede llegar a anular y destruir al hombre, o bien porque puede perderse en la angustia de la propia miseria, o el hacer la "vista gorda" frente a ella, para evitar descubrirse diferente a los parámetros sociales o idealismos personales (es la peligrosa actitud del no aceptarse a sí mismo).

En el fondo no se trata más que de la actitud fundamental del ser humano que busca entender el sentido de su existencia. Sólo que en el caso de Teresa ese sentido se observa y complementa a la luz de una comprensión teologal del hombre que se descubre "criatura" y no "señor" 26.

25 P. Cerezo Galán, La experiencia..., p. 203, afirma: "En una época por lo demás egoísta y secularizada, en que el hombre, como un nuevo Narciso, encuentra por doquier los vestigios de su propia imagen hasta perecer ahogado en el laberinto de inacabables espejos, Teresa de Ávila descubría aquel otro espejo interior, bruñido de silencio y ansias, en que la i m a g e $n$ se trasciende a sí misma en su original. Erael quiebro máselegante, la ironía más fina que se podía imaginar contra el mero humanismo. Y es que toda proyección de si es de corto radio, o se extravía en infinitos ilusorios -humanos, demasiado humanos, multiplicados fetiches de sí mismo-, si no se proyecta en ella el ansia viva o el deseo transfigurado de un Dios más grande que nuestra miseria y más fuerte que la muerte".

26 Es la actitud que continuamente Teresa manifiesta en su vida después de su conversión definitiva: (cfr. V 3, 5: "vine a ir entendiendo la verdad de cuando niña, de que no era todo nada, y la vanidad del mundo, y cómo acababa en breve, y a temer, si me hubiera muerto, cómo me iba al infierno"; cfr. V 15, 11: "que todo (lo creado) era nada"). En esa misma dinámica plantea Juan de la Cruz el inicio de todo el proceso espiritual (cfr. CB 1, 1). 
Un aspecto importante que acarrea consigo el conocimiento propio, junto al descubrimiento de la propia dignidad, es el reconocimiento de la dignidad del otro. Descubriendo la raíz y fundamento de aquello que da un valor infinito a mi ser, como consecuencia necesaria descubro que ese fundamento está a la base del sentido y valor de todo ser humano, al que ya no podré percibir de otra manera.

\section{Fundamentos de la dignidad Del Ser humano}

En el apartado anterior me he detenido someramente a evidenciar la centralidad del conocimiento de sí en la obra teresiana y en todo el proceso espiritual y místico, casi como la piedra angular sobre la cual se ha de construir todo el edificio de la persona, como dice repetidas veces Teresa "lo que más nos importa" 27. Este acercamiento nos ayuda a percibir de manera inequívoca, que la comprensión que Teresa alcanza de la interioridad del ser humano, no es el simple resultado de unas creencias religiosas, o de una simple intuición de fe. Emerge en el contacto mismo con la subjetividad inherente al ser humano.

En sus obras, tal como hemos ido insinuando, es siempre un tema fundamental, aunque no se le dedique un apartado exclusivo o haga grandes discursos sobre el tema ${ }^{28}$. Pero será sobre todo en Moradas donde aparece con toda su fuerza y valor capital dentro de lo que podríamos denominar el camino de crecimiento de la persona humana (tanto en la perspectiva antropológica como mística). La persona crece en la medida en que descubre y abre los ojos al verdadero valor de su propio ser.

De hecho, el planteamiento que acompaña todo el proceso que Teresa ofrece en Moradas, ya intuitivamente y explícitamente se fundamenta en el conocimiento de sí. El camino consiste en conocer las diversas moradas que encontramos en nuestro castillo interior. No se trata de un camino "ad extra" sino "ad intra". Teresa en el planteamiento general de la obra ya nos hace ver cómo todo el camino espiritual se confunde con el "proceso de conocimiento de sí". Podríamos hasta afirmar que el dinamismo del proceso místico que Teresa presenta en su obra central se basa en ello: ayudarnos a conocer esa interioridad que

$27 \quad 1 \mathrm{M} 2,13$.

28 Sobre el tema del conocimiento de síen Teresa no hay mucho escrito. Tuve ocasión de escribir sobre el tema en relación con el Libro de la Vida F. J. SANCHO FER Mín, El conocimiento de sí en la meditación teresiana, en Id. (coord.), La meditación teresiana, CITeS-Universidad de la Mistica, Ávila 2012 ( $2^{\mathrm{a}} \mathrm{ed}$ ), pp. 51-90. También la intervención de E. Münzebrock, La importancia y relevancia del conocimiento de sí en el proceso espiritual de Teresa, a la luz del Libro de la Vida, en F. J. Sancho - R. Cuartas (dir.), El Libro de la Vida de Santa Teresa de Jesús. Actas del I Congreso Internacional Teresiano, Monte Carmelo-Universidad de la Mistica-CITeS, Burgos 2011, pp. 397 ss. 
somos cada uno, descubrir lo que puede acontecer en ella, y lo que nos vamos a encontrar.

Una advertencia a tener en cuenta: quién está habituado a leer los escritos de la Santa abulense, enseguida se percata de la constante insistencia con la que ella se presenta a sí misma: se autodenomina mujer ruin y pecadora, subrayando, como si se tratase de un estribillo, su miseria. Estas afirmaciones corren el riesgo de acabar creando en el lector la "sensación" de que Teresa tiene un concepto muy negativo de sí misma, y puede llevarle a la conclusión equivocada de que lo importante en el proceso es reconocer constantemente la "propia miseria", casi como si se tratase de la condición única que define al sujeto.

Pero lo cierto es que esa conclusión, que puede alterar totalmente la comprensión del humanismo de base que Teresa nos quiere transmitir, no es un absoluto en la comprensión que Teresa tiene de sí misma y que nos presenta del mismo ser humano en general. Sí, es cierto, la experiencia de la limitación, de la miseria, del no gustarse a sí mismo, etc... son realidades que acompañan el proceso humano del conocimiento de sí; pero ahí ni se agota la comprensión de lo que somos, ni mucho menos es la dimensión de nuestro ser que verdaderamente nos define. En este sentido, la dinámica que encontramos en la obra de las Moradas nos convencerá con suficiente nitidez de que, en el fondo, la visión antropológica de Teresa es, por el contrario, tremendamente positiva.

Y desde las primeras líneas del Castillo Interior queda constancia de ello. Teresa toma como punto de partida de esta obra y del camino que nos va a proponer, la presentación de aquello que verdaderamente somos, lo que nos define: el ser humano es en su interioridad, en su alma (es decir, en aquello que sustenta y rige su vida), un ser de una hermosura inigualable, un ser que lejos de carecer de sentido o de estar vacío por dentro, está habitado por el mismo Dios; un ser, en definitiva, que es imagen y semejanza de $\operatorname{Dios}^{29}$. No se puede decir más de la grandeza y dignidad del ser humano en tan pocas líneas:

para comenzar con algún fundamento: que es considerar nuestra alma como un castillo todo de un diamante o muy claro cristal, adonde hay muchos aposentos... Que si bien lo consideramos, hermanas, no es otra cosa el alma del justo sino un paraíso adonde dice El tiene sus deleites. Pues ¿qu ú tal os parece que será el aposento adonde un Rey tan poderoso, tan sabio, tan limpio, tan lleno de todos los bienes se de leita? No hallo yo cosa con que comparar la gran hermosura de un alma y la gran capacidad; y verdaderamente apenas deben llegar nuestros entendimientos, por agudos que fuesen, a comprenderla, así como no pueden 
llegar a considerar a Dios, pues El mismo dice que nos crió a su imagen y semejanza. Pues si esto es, como lo es, no hay para qué nos cansar en querer comprender la hermosura de este castillo; porque puesto que hay la diferencia de él a Dios que del Criador a la criatura, pues es criatura, basta decir $\mathrm{Su}$ Majestad que es hecha a su imagen para que apenas podamos entender la gran dignidad y hermosura del ánima ${ }^{30}$.

No encontraremos ningún otro párrafo en que se fundamente de manera tan positiva y radical lo que define al ser humano.

Por bien 3 veces repite Teresa el calificativo "hermosura". Este texto es el punto de partida, donde plasma con solemnidad su definición y comprensión de la dignidad del ser humano. De hecho el proceso espiritual que propone Teresa como fruto de su larga experiencia mística, consiste principalmente en ir ahondando y descubriendo cada vez más esa gran "hermosura" escondida, y que por "nuestra culpa" tantas veces somos incapaces de descubrir. Teresa pone aquí el quid de la cuestión, y hasta podríamos decir que la razón por la cual los humanos somos tan miserables: porque no conocemos la gran dignidad que hay en nosotros. Este era el argumento para explicar el por qué de tantas injusticias. Ahora vuelve sobre ello, lamentando que nos perdamos lo mejor de la vida por no abrir los ojos a nuestra verdadera condición:

No es pequeña lástima y confusión que, por nuestra culpa, no entendamos a nosotros mismos ni sepamos quién somos. ¿No sería gran ignorancia, hijas mías, que preguntasen a uno quién es, y no se conociese ni supiese quién fue su padre ni su madre ni de qué tierra? Pues si esto sería gran bestialidad, sin comparación es mayor la que hay en nosotras cuando no procuramos saber qué cosa somos, sino que nos detenemos en estos cuerpos, y así a bulto, porque lo hemos oído y porque nos lo dice la fe, sabemos que tenemosalmas. Mas qué bienes puede haber en esta alma oquién está dentro en esta alma o el gran valor de ella, pocas veces lo consider a mos; y así se tiene en tan poco procurar con todo cuidado conservar su hermosura: todo se nos va en la grosería del engaste o cerca de este castillo, que son estos cuerpos ${ }^{31}$.

Pero todavía hay más. Esta descripción que hace Teresa del ser humano, sintetiza lo esencial del proceso que nos va a presentar: conocer, rescatar y vivir la grandeza de lo que somos. En este sentido ya Teresa nos transmite cómo su insistencia en el "conocimiento de sí" no se reduce a una percepción psicologista 
o simplemente antropológica de lo que somos, sino que desde esos interrogantes existenciales podemos caminar hacia una plenitud que está al alcance de la mano de todos, porque es lo que nos define como seres humanos. Y porque, además, pone de manifiesto lo que somos para Dios: seres con un valor incalculable, infinito, y en quienes Dios ha puesto y pone su confianza: Dios ha establecido su morada en el interior de cada hombre, a pesar de su condición débil y pecadora.

Teresa se manifiesta profundamente inteligente y sabia con este fundamento que da al camino espiritual: avanzar en el camino místico será un proceso de humanización, porque en lo "humano" se encuentra la grandeza de lo que somos y de lo que Dios nos ha dado y forjado en cada uno de nosotros. Una visión tan positiva del ser humano solo emerge en Teresa cuando, después de haber recorrido todo el proceso, llega a percatarse de que Dios nos une consigo en nuestra humanidad, porque quiere ensalzarla y plenificarla. Y en ese camino el hombre adquiere un protagonismo de colaboración que está inscrito en su propio ser. Por eso Teresa nos va a invitar constantemente a no quedarnos en "nuestra miseria" porque así nunca avanzaremos ni llegaremos a la morada donde habita el Rey.

Este punto de partida teresiano, que se convertirá en el punto de llegada (cf. M epílogo 3), nos abre hacia la comprensión y necesidad que ella manifiesta en relación con la vida mística.

De aquí que el conocimiento de sí nunca llegará a ser total si la persona no se acerca al Misterio. En Él se nos desvela la identidad más profunda de lo que somos: "pues en nosotros mismos están grandes secretos que no entendemos" ${ }^{2}$. Para Teresa es el encuentro con el Misterio lo que nos va llevando a una comprensión de lo que somos en verdad.

Abriéndose al Misterio, la persona puede llegar a un conocimiento mayor de sí. Pero no solo eso, sino que aprenderá a actuar desde la positividad infinita que la define, en vez de quedarse en la limitación de su miseria. Así lo expresa Teresa:

¿Oh que si es en el propio conocimiento! Que con cuán necesario es esto (miren que me entiendan), aun a las que las tiene el Señor en la misma morada que El está, que jamás - por encumbrada que esté- le cumple otra cosa ni podrá aunque quiera; que la humildad siempre labra como la abeja en la colmena la miel, que sin esto todo va perdido. Mas consideremos que la abeja no deja de salir a volar para traer flores; así el alma en el propio conocimiento, créame y vuele algunas veces a considerar la grandeza y majestad de su Dios. Aquí hallará su bajeza mejor que en sí misma, y más libre de las sabandijas

$324 \mathrm{M} 2,5$ 
adonde entran en las primeras piezas, que es el propio conocimiento; que aunque, como digo, es harta misericordia de Dios que se ejercite en esto, tanto es lo de más como lo de menos-suelen decir-. Y créanme, que con la virtud de Dios obraremos muy mejor virtud que muy atadas a nuestra tierra ${ }^{33}$.

Teresa nos invita a abrirnos al Misterio como la vía que hace posible reconocer nuestra condición más auténtica. Cerrarnos o ensimismarnos en nosotros mismos no ha de entenderse solamente en sentido voluntarista, pues se corren muchos riesgos si no nos abrimos a la dimensión positiva de lo que somos:

Que todo esto les parece humildad, y otras muchas cosas que pudiera decir, y viene de no acabar de entendernos; tuerce el propio conocimiento y, si nunca salimos de nosotros mismos, no me espanto, que esto y más se puede temer... y no hará el propio conocimiento ratero y cobarde; que, aunque ésta es la primera morada, es muy rica y de tan gran precio, que si se descabulle de las sabandijas de ella, no se quedará sin pasar adelante ${ }^{34}$.

\section{La toma de CONCIENCIA De Nuestra "Grandeza" NOS LLEVA A ACTUAR POSITIVAMENTE}

La consideración de la grandeza de lo que somos potencia en nosotros la capacidad de actuar positivamente. Es un principio claro y evidente en Teresa, tal como hemos constatado; y es un principio que hoy ponderan muchas corrientes y movimientos centrados en ayudar al ser humano en su realización. Teresa, a pesar de las muchas limitaciones que tuvo que sufrir en su vida, tanto por sus enfermedades, como por su condición de mujer en el siglo XVI, no se encerró en un inútil lamentarse, ni dejó apocar sus "sueños" y sus deseos de actuar conforme a ellos. Es más, ella descubre, a pesar de todo, que una hormiga puede hacer grandes cosas:

:Oh grandeza de Dios! iY cómo mostráis vuestro poder en dar osadía a una hormiga! iY cómo, Señor mío, no queda por Vos el no hacer grandes obras los que os aman, sino por nuestra cobardía y pusilanimidad! Como nunca nos determinamos, sino llenos de mil temores y prudencias humanas, así, 
Dios mío, no obráis vos vuestras maravillas y grandezas. ¿Quién más amigo de dar, si tuviese a quién, ni de recibir servicios a su costa? ${ }^{35}$;

y por eso aconseja siempre aspirar a grandes cosas, a no apocar el alma:

es amigo de ánimas animosas, como vayan con humildad y ninguna confianza de sí. Y no he visto a ninguna de éstas que quede baja en este camino; ni ninguna alma cobarde, con amparo de humildad, que en muchos años ande lo que estotros en muy pocos. Espántame lo mucho que hace en este camino animarse a grandes cosas; aunque luego no tenga fuerzas el alma, da un vuelo y llega a mucho, aunque -como avecita que tiene pelo malo-cansa y queda ${ }^{36}$.

Estos textos dejan una vez más en evidencia el humanismo positivo subyacente a toda experiencia mística auténtica.

Hasta ahora hemos asistido a un contraste o incluso apreciación contradictoria en los elementos que definen el conocimiento de sí: miseria y grandeza. Ambas realidades forman parte de la verdad de lo que somos. Estamos frente a una moneda con dos caras, y ambas forman parte del ser de la persona, si bien no en las mismas condiciones. Si prestamos atención a la imagen que usa Teresa para describir a la persona humana, como un castillo de diamante o de cristal, la condición de miseria no forma parte integrante del castillo, es algo que está fuera, que le puede manchar u oscurecer, pero no cambia ni altera la naturaleza del castillo. Ello significa que lo que verdaderamente nos identifica, y hacia donde ha de caminar el conocimiento, es al descubrimiento de la grandeza y hermosura del propio castillo, es decir, superar la visión superficial y materialista del ser humano que termina por anular su verdadera condición, tanto en el campo religioso que acentúa solo la condición de pecado, como en el campo social, que termina por reducir al ser humano a lo que tiene, produce o consume.

Esta perspectiva es algo que va haciéndose patente según nos metemos en nuestro propio castillo y dejamos que las sabandijas se queden fuera:

Como ya estas moradas se llegan más adonde está el Rey, es g rande su her mosura y hay cosas tan delicadas que ver y que entender, que el entendimiento no es capaz para poder dar traza cómo se diga siquiera algo que venga tan al justo que no quede bien oscuro para los que no tienen experiencia; que quien la tiene muy bien lo entenderá, en especial si es mucha ${ }^{37}$.

$35 \quad F 2,7$.

$36 \mathrm{~V} 13,2$.

$374 \mathrm{M} 1,2$ 
Teresa nos enseña a ver lo positivo del ser humano, aún en el descubrimiento de nuestra miseria y pobreza:

¡Oh ceguedad humana! ¿Hasta cuándo, hasta cuándo se quitará esta tierra de nuestros ojos? Que aunque entre nosotras no parece es tanta que nos ciegue del todo, veo unas motillas, unas chinillas, que si las dejamos crecer bastarán a hacernos gran daño; sino que, por amor de Dios, hermanas, nos aprovechemos de estas faltas, para conocer nuestra miseria y ellas nos den mayor vista, como la dio el lodo del ciego que sanó nuestro Esposo; y así, viéndonos tan imperfectas, crezca más el suplicarle saque bien de nuestras miserias, para en todo contentar a Su Majestad ${ }^{38}$.

Se convierte en una constante en el camino, incluso en las cimas más altas de la vida mística.

Podría alegarse, tal como a veces se entiende erradamente, que el "conocerse" es sólo una fase del camino. Para Teresa en nuestra humanidad se radica nuestro verdadero tesoro y dignidad. Y no dejará de recordarlo con insistencia, incluso al final de la obra de "Las Moradas": "Aunque no se trata de más de siete moradas, en cada una de éstas hay muchas: en lo bajo y alto y a los lados, con lindos jardines y fuentes y laberintos y cosas tan deleitosas, que desearéis deshaceros en alabanzas del gran Dios, que lo crió a su imagen y semejanza" ${ }^{39}$.

\section{LA DigNidAd y BELleza INALIENABle DE LA PERSONA}

A manera de síntesis, podemos concluir subrayando el proceso pedagógico y formativo que Teresa nos traza para hacer el camino místico. Insinuábamos que Teresa comienza este itinerario como si quisiera responder a una pregunta inicial necesaria: ¿quién es el hombre? Es, para Teresa, la base o roca sólida donde se construye el castillo de la vida de la persona. De otro modo se corre el riesgo de comenzar a construir castillos en el aire o sobre arena, forjando la vida o el sentido de la misma sobre realidades caducas o temporales, con lo cual el riesgo de perder el horizonte es permanente. En este sentido, conviene evidenciar cuanto Teresa trata de fundamentar en el hombre desde una comprensión teologal del mismo.

Para Teresa, la persona que quiere caminar con paso firme hacia su plenitud y felicidad, ha de considerar y acoger su verdadera condición, que ella define en estos enunciados:

$386 \mathrm{M} 4,11$.

39 Mepílogo 3. 
El hombre es "Habitación de Dios" ${ }^{40}$. Esta primera imagen por orden de aparición en esta obra teresiana, subraya no solo una concepción elevadísima de lo que es el ser humano. Podría resultar una afirmación ingenua, como repetición de una cierta visión religiosa del hombre. Pero lo cierto es que tal afirmación encierra un contenido mucho más grande de lo que aparentemente refleja. Decir que el hombre es "habitado por el mismo Dios", quiere decir que cuánto le constituye como tal es una Presencia, una presencia que nunca desaparece, por lo que la dignidad es un valor permanente en el ser humano, y que nadie le puede robar. Es el encuentro con la belleza que somos y que nunca se pierde: "Es de considerar aquí que la fuente y aquel sol resplandeciente que está en el centro del alma no pierde su resplandor y hermosura que siempre está dentro de ella, y cosa no puede quitar su hermosura"41. Este principio ofrece una visión holística del valor infinito del ser humano frente a sí mismo, que nunca pierde su calidad, aún cuando él mismo crea haberla perdido. Dios permanece siempre fiel a su criatura, con lo que para Teresa el ser humano tiene asegurada su dignidad en un principio infinito y no caduco. Ello implica, además, que el ser humano, aún con sus deficiencias, es sujeto de una confianza constante en él por parte de Dios. Esta comprensión antropológica le abre al místico a la comprensión de que Dios no espera ni exige nada al hombre que antes no nos haya dado en abundancia. Ello planteará un gran reto a la vida de fe del creyente: sumergirse en ver cómo y quién es Dios para él. Para Teresa una comprensión fundante de lo que es el hombre nos ancla aún más en el ser de Dios.

El hombre es Imagen y semejanza de Dios: es la concepción bíblica del hombre por excelencia. Las implicaciones que esta afirmación conlleva aparecen desde el inicio en el libro de Moradas. Para Teresa es la justificación antropológica de que su experiencia mística tiene un fundamento en la propia humanidad. Que no se trata de algo subjetivo, sino de algo que corresponde al ser que define la existencia del hombre y su razón de ser. La raíz y fundamento de su dignidad. La experiencia mística que asume este principio como un dogma fundamental, se abre a un descubrimiento nuevo de lo que en sí es el ser humano.

Todo ello fundamenta que se pueda hablar de la gran dignidad y hermosura del alma. Sí, Teresa no deja de hablar de la miseria, el pecado, la pequeñez, la indignidad, etc... que forman parte de lo que es el hombre. Pero eso no agota, ni mucho menos su ser. El principio que regirá el camino de la vida espiritual apunta a descubrir la percepción que Dios mismo tiene del hombre, y, por lo tanto, a asumir ese principio de credibilidad. Es la dimensión más

$40 \quad 1 \mathrm{M} 1,1$.

$41 \quad 1 \mathrm{M} 2,3$. 
auténtica del hombre. No nos define el pecado, sino el ser imagen; no nos define ni agota la limitación, sino nuestra inserción en el infinito... Por eso la persona humana goza de la misma dignidad que el principio del cual se deriva su ser y existencia. Nuestro pecado, nuestra miseria... muchas veces son un freno para avanzar en el camino del crecimiento, porque nos impiden ahondar en el castillo donde nos encontramos con Dios... Pero el tomar como punto de partida, no la suciedad que envuelve al diamante, sino la convicción de la existencia de ese diam an te tras la capa de suciedad, eso ha de ser motor de una mística viva y dinámica, anclada en el ser del hombre. En este sentido creo que Teresa acierta plenamente en su punto de partida.

Pero esa visión no se encierra en la comprensión de lo que es el hombre en sí mismo. La experiencia y apertura interior al propio ser nos abre constantemente a la percepción de la gratuidad, del descubrir que lo que me define e identifica es algo que me ha sido dado gratuitamente: lo cual, desde la perspectiva de la vivencia mística teresiana encuentra su revelación más profunda en el misterio de la redención. Saberse redimido por Cristo:

¿Oh almas redimidas por la sangre de Jesucristo! iEntendeos y habed lástima de vosotras! ¿Cómo es posible que entendiendo esto no procuráis quitar esta pez de este cristal? Mirad que, si se os acaba la vida, jamás tornaréis a gozar de esta luz. iOh Jesús, qué es ver a un alma apartada de ella! ${ }^{42}$

Pero como venimos subrayando desde el inicio, la experiencia mística no se fundamenta en verdades teóricas o principios, por muy grandes que estos puedan ser. La mística auténtica se justifica en el dinamismo de la vida que asume y hace suyos esos principios, dejándose transformar y revitalizar por ellos. Y en esa dinámica se mueve Teresa. Y desde aquí podemos entender el porqué una experiencia mística auténtica y duradera, termina por forjar en la persona un proceso de madurez y de realización de su propia humanidad, aún con sus deficiencias y limitaciones.

\section{A MODO DE CONCLUSIÓN}

Esas verdades conocidas por la fe y reconocidas por la experiencia, van forjando las consecuencias existenciales para el ser humano, y para el místico. Estas consecuencias nos las presenta Teresa como un reto, como una verdadera motivación para no dejar de recorrer esta fascinante aventura de la auténtica humanización.

$42 \quad 1 \mathrm{M} 2,4$ 
Dios no puede no habitar sino en un lugar hermoso, ¿cómo no aventurarnos en este camino hasta la propia interioridad, y descubrir que en nuestra interioridad se encuentra el tesoro más grande que podemos alcanzar?:

¿qué tal os parece que será el aposento adonde un Rey tan poderoso, tan sabio, tan limpio, tan lleno de todos los bienes se deleita?... Pues si esto es, como lo es, no hay para qué nos cansar en querer comprender la hermosura de este castillo... ${ }^{43}$

Necesidad de ser consecuentes con nuestro ser auténtico, y tratar de ahondar en cuanto nos manifiesta, especialmente en relación con lo que somos en nuestro interior. La consecuencia es que tenemos que interiorizarnos, conocernos, si queremos encontrarnos con el sentido y valor de nuestra vida y alcanzar la plenitud y la felicidad:

por nuestra culpa, no entendamos a nosotros mismos ni sepamos quién somos... es mayor la que hay en nosotras cuando no procuramos saber qué cosa somos, sino que nos detenemos en estos cuerpos, y así a bulto, porque lo hemos oído y porque nos lo dice la fe, sabemos que tenemos almas. Mas qué bienes puede haber en esta alma o quién está dentro en esta alma o el gran valor de ella, pocas veces lo consideramos; y así se tiene en tan poco procurar con todo cuidado conservar su hermosura: todo se nos va en la grosería del engaste o cerca de este castillo, que son estos cuerpos ${ }^{44}$.

Al fin y al cabo, el camino místico y el camino del conocimiento y realización de nuestra dignidad, confluyen en un mismo fin y proyecto, "pues en nosotros mismos están grandes secretos que no entendemos" 45 . 


\title{
STRESZCZENIE
}

\author{
Francisco Javier Sancho Fermín \\ Mistyka terezjańska jako droga ku cztowieczeństwu
}

Spojrzenie, jakie zwykle mamy na temat mistyki lub mistyków, zawęża się do sfery zjawisk nadzwyczajnych lub do stylu życia w zamknięciu i odcięciu się od rzeczywistości. Tymczasem autentyczni mistycy są chrześcijanami, którzy radykalnie żyją Ewangelią i poczuwają się do prawdziwego i konkretnego angażowania się w to, co ludzkie.

Teresa od Jezusa i jej doświadczenie Boga są namacalnym przykładem na to, czym jest prawdziwa mistyka chrześcijańska. Taka mistyka nie oddala wierzącego od konkretnej rzeczywistości, lecz prowadzi do odkrycia jej prawdziwego znaczenia i zaangażowania się w nią.

Co więcej, wraz z niewyrażalnością, z którą związane jest doświadczenie mistyczne, rodzi się, jako konsekwencja i dowód jego autentyczności, bezpośrednie zaangażowanie we wszystko, co dotyczy godności bytu ludzkiego.

W artykule usiłujemy ukazać wymiar mistyki terezjańskiej, w którym spotkanie $z$ Misterium prowadzi do tego, co najgłębsze w zrozumieniu godności bytu ludzkiego. To głębokie doświadczenie sprawia, że mistyka terezjańska wyrasta $z$ wielkości bytu ludzkiego, stworzonego na obraz i podobieństwo Boga, zamieszkiwanego przez Boga i mającego niezniszczalne pięlno, porównywane do diamentu. Żadna antropologia nie osiagnęła tak szerokiego i pozytywnego zrozumienia bytu ludzkiego jak to, które wyłania się z doświadczenia Boga.

Zrozumienie wielkiej godności i piękna bytu ludzkiego w mistyce terezjańskiej znajduje odzwierciedlenie w życiu i w zaangażowaniu na rzecz innych, zwłaszcza w ukierunkowaniu na służbę i miłość bliźniego. Według św. Teresy od Jezusa, w tym weryfikuje się autentyczność doświadczenia mistycznego, że „z niego rodzą się czyny".

Poznanie godności bytu ludzkiego w mistyce Teresy prowadzi do przeobrażenia etycznego osoby, uzdrowienia jej ran i ukazuje nieodzowność poznania siebie samego.

Autor artykułu stara się ukazać, że prawdziwa mistyka czyni człowieka bardziej ludzkim i zaangażowanym w przekształcanie rzeczywistości. 


\section{ABSTRACT \\ Francisco Javier Sancho Fermín \\ Teresian Mysticism as a Path Towards Humanism}

Our ideas regarding mysticism or mystics are usually associated with supernatural phenomena or with living an enclosed life cut off from reality. In contrast, however, authentic mystics are Christians who live the Gospel in its radicalism and are moved to a genuine and practical involvement with everything that is human.

Teresa of Jesus and her experience of God are a tangible example of true Christian mysticism. Such mysticism does not draw the faithful away from a specific reality but leads them to discover its real meaning and to engage in it.

Moreover, along with the inexpressibility linked to a mystical experience comes a consequence and a proof of authenticity in the form of a direct engagement into everything related to the dignity of the human person.

This article attempts to show the dimension of teresian mysticism in which our encounter with the Mystery leads to the deepest understanding of the dignity of the human person. This profound experience is the reason why teresian mysticism is founded on the greatness of our humanity created, as it is, in the image and likeness of God, who dwells within each one of us. As a consequence our soul has an indestructible beauty which can be likened to a precious diamond. No anthropology has ever reached such a deep and positive understanding of the human person coming as it does from an experience of God.

The awareness of the great dignity and beauty of the human person within teresian mysticism can be glimpsed in daily life and in our engagement with others, especially in the service to and the love of our neighbors. According to St Teresa, the authenticity of a mystical experience is verified through the fact that "it results in deeds".

The understanding of the dignity of the human person in teresian mysticism leads to an ethical transformation within a person and to the healing of his or her wounds. It also points to the importance of self-knowledge.

The author of this article has tried to demonstrate that true mysticism makes us more human and more involved in the transformation of reality.

Słowa klucze: mistyka terezjańska, św. Teresa z Awili, doświadczenie Boga, człowieczeństwo, godność człowieka

Keywords: teresian mysticism, St Teresa of Avila, experience of God, humanism, dignity of human being 